\title{
Analysis of Engineering Students' Common Difficulties with DC Electric Circuits in An Inquiry-Based Laboratory
}

\author{
Victor Travagin Sanches* \\ *Instituto de Física, Universidade de São Paulo, São Paulo, Brazil. \\ E-mail: victortravagin@usp.br \\ Gláucia Grüninger Gomes Costa* \\ •Instituto de Física de São Carlos, Universidade de São Paulo, São Carlos, Brazil. \\ E-mail: gggcosta@ifsc.usp.br \\ Jéssica Fabiana Mariano dos Santos` \\ `Instituto de Física de São Carlos, Universidade de São Paulo, São Carlos, Brazil. \\ E-mail: jessica.santos@usp.br

\section{Tomaz Catunda”} \\ 'Instituto de Física de São Carlos, Universidade de São Paulo, São Carlos, Brazil. \\ E-mail: tomaz@ifsc.usp.br
}

\begin{abstract}
The students' understanding about direct current concepts of Electric Circuits has been extensively investigated in secondary schools as well as in Universities. At the São Carlos Institute of Physics/University of São Paulo (IFSC/USP), for more than 10 years, our group has been researching the Electricity and Magnetism Laboratory Course to Engineering students. Similarly to
\end{abstract}


reported in literature, we also observed that students often finish Physics classes with less understanding of Physics concepts than we expected. In this paper, we present an investigation of students' difficulties about direct current concepts of Electric Circuits. In addition, this research was used as a guide for development and evaluation of the Electricity and Magnetism laboratory classes. Our research was initiated on 2006, with a question similarly to developed by McDermott to investigate students' conceptual understanding of Direct Current Electric Circuits. This question was applied to students of Science, Technology, Engineering and Mathematics (STEM) areas, after students attended the theoretical and laboratory courses. They had to order light bulbs according to brightness in three different electric circuits to answer the question. Only about $13,0 \%$ of students answered correctly, which agreed to result in other countries and inspired us to restructure the Laboratory Guide. Our new guide was inquiry-based with some activities adapted from Tutorials in Introductory Physics and others developed in a prediction-observation-explanation form. The same question was used as pre and post-test and the average percentage of students who got the maximum score was about $47,0 \%$. We also have been using the Determining and Interpreting Resistive Electric Circuit Concepts Test (DIRECT), which is composed by a 29-multiple choice questions, that can be grouped in conceptual objectives, allowing us to identify specific conceptual difficulties. We proposed many modifications in the students' guide, after analyzing their answers and some of them we managed to improve, like those related to resistance and current. On the other hand, less than $50,0 \%$ of students could answer correctly some questions related to the concepts of power and voltage in the post-test, even after our efforts to improve learning in this aspect. We have been able to help students overcome known conceptual difficulties with the proposal of new activities, but some difficulties are still a challenge to be outgrown. This fact has shown us that research for improving practice is fundamental to overcome persisting difficulties and it is a long-term and constant action. Also, using different resources such as homework activities on the internet, videos and computer simulations have shown to be useful supplementary tools.

Keywords: Electric Circuits, Inquiry, Laboratory, STEM, Undergraduate.

\section{Introduction}

Literature on college physics students' understanding converges that traditionally taught courses do little to improve students' understanding of the central concepts of physics ${ }^{1-3}$. Often, even in the laboratory courses is observed that students follow a script in which they are not encouraged to think about their own actions. This kind of laboratory, based in "transmission" model (also called "cookbook" style), is highly ineffective for teaching twenty-first century competencies and skills. To develop higher-order skills, individuals must engage in meaningful inquiry-based learning ${ }^{4}$.

In the last decades, researches in Physics teaching have given special attention to Direct Current (DC) Electric Circuits, which is studied in high school and in college. It is consensus that students still show some conceptual difficulties, even after attending to Physics' lectures and laboratories ${ }^{1-3,5-7}$. The DC Electric Circuits plays a significant role in curriculum of Engineering students. In the National Curricular Guidelines for Engineering Teaching ${ }^{8}$ (in Portuguese, "Diretrizes Curriculares Nacionais para o Ensino de Engenharia", or simply DCN), about 15 topics (approximately 30,0\% of the total course program) can be related directly with the Electricity and Magnetism laboratory course, like Scientific and Technological Method, Physics, Math and Applied Electricity. Besides, in article 4, 13 several competences and skills are defined as required to the professional in Engineering, of which we highlight four, also related to Physics Lab:

- Apply Math, Physics, scientific, technological and instrumental knowledge to Engi- 
neering;

- To project and conduct experiments and interpret results;

- Critically evaluate the operation and maintenance of systems; and

- To communicate efficiently in oral, written and graphical form.

In order to improve learning of fundamental concepts about DC Electric Circuits and add other elements to students' intellectual development, the Electricity and Magnetism Laboratory of our institution have been modified, making students active in their learning processes. To do that, we adapted the Tutorials in Introductory Physics ${ }^{9}$. Tutorials were developed using inquiry activities in which students make predictions, observations e comparisons. In the end, they summarize their answer synthesizing reasoning by using evidences and hypothesis. In these classes, students are guided through activities with emphasis in discovery rather than in memorization. Thus, students can infer mathematical relations between the variables involved in the phenomenon studied.

By these competences, skills and contents, defined in the DCN, we conclude that Physics and specially the inquiry Physics Laboratory, has potential to develop the above-mentioned points and is also a rich environment for learning research. The inquiry methodology offers students the possibility to reflect about problems and confront their predictions with results acquired. Students can also propose new experiments so that their hypotheses are tested.

The data collection and analysis, was developed by the open question showed in Frame 1, adapted from McDermott and Shaffer ${ }^{1}$ which is used as pre and post-test since 2009. To analyze students' comprehension about specific concepts, we also have used the "Determining and Interpreting Resistive Electric Circuit Concepts Test"3 (DIRECT) since 2013. It is a multiple-choice test, composed by 29 questions of which we used 28 questions. Researches have shown us that students improved significantly their skills after the laboratory classes, although there are still some persistent difficulties.

In this work, we highlight the most common students' difficulties, comparing results of pre and post-test, and comment about our actions to improve learning.

\section{Methodology}

The Electricity and Magnetism Laboratory lasts for one semester and has six classes, four hours each. In each class, there are about 30 students, divided in 10 groups of three students. They make six different practices along the laboratory.

The Laboratory Guide has a small introduction for each practice and questions that follows a sequence of prediction-observation-explanation, in which students build relations between variables involved in the model studied. At the end of each practice, there is a list of exercises for students to consolidate and improve knowledge. The physics concepts are introduced through the laboratory and experiments are made in a growing level of complexity. Students are asked to discuss and register answers to experiments and, if there is any diversion of opinion they also must register. Doubts related to each experiment or section must be solved (through discussion between group members and monitored by the Professor Assistant and the Professor) before proceeding with the experiment.

At the end of each practice, students have to make a report consisting in their answers to the guide's questions, the data collected and explanations. The assessment is made by those reports and 3 tests along the laboratory course.

To evaluate the guide, we applied the same question (Open Question) as pre and posttest in Frame 1. The post-test is applied three months after the laboratory's experimental practice about DC circuits. We also have applied 28 of the 29 DIRECT's questions (the 
questions not used is about a subject not treated in the course).

Frame 1. Open Question, adapted from McDermott and Shaffer ${ }^{1}$.

A light bulb is a resistance. If this bulb is ideal, it means that it's resistance is constant and obeys Ohm's
Law. Suppose that four identical light bulbs (A, , , , D) and an ideal battery $\left(\mathrm{V}_{0}\right)$, that compose circuits in
figures (I, II, III). For each case, [(I), (II) e (III)], classify the light bulbs in growing order of brightness.
Explain your reasoning.
(I)

The DIRECT was introduced by Engelhardt ${ }^{3}$ on her PhD thesis. The main objective of this test is to provide a tool to measure the extent of conceptual understanding of students regarding DC concepts. DIRECT's questions can be grouped in 11 learning objectives ${ }^{3}$, as showed in the Frame 2.

Comparing students' answers to pre and post-tests we are able to see if there was an increase in the number of students who answered correctly each question. In this way, we could map students' common difficulties and propose new activities to improve learning.

Frame 2. DIRECT's objectives per question. Reproduced from Engelhardt ${ }^{3}$.

\begin{tabular}{|c|c|}
\hline Objective & Question Number \\
\hline \multicolumn{2}{|l|}{ Physical Aspects of DC electric circuits (objectives $1-5$ ) } \\
\hline $\begin{array}{l}\text { (1) Identify and explain a short circuit (more current follows the } \\
\text { path of lesser resistance). }\end{array}$ & $10,19,27$ \\
\hline $\begin{array}{l}\text { (2) Understand the functional two-endedness of circuit elements } \\
\text { (elements have two possible points with which to make a connec- } \\
\text { tion). }\end{array}$ & 9,18 \\
\hline $\begin{array}{l}\text { (3) Identify a complete circuit and understand the necessity of } \\
\text { a complete circuit for current to flow in the steady state (some } \\
\text { charges are in motion but their velocities at any location are not } \\
\text { changing and there is no accumulation of excess charge anywhere } \\
\text { in the circuit). }\end{array}$ & \\
\hline Objectives $1-3$ combined & 27 \\
\hline $\begin{array}{l}\text { (4) Apply the concept of resistance (the hindrance to the flow of } \\
\text { charges in a circuit) including that resistance is a property of the } \\
\text { object (geometry of object and type of material with which the } \\
\text { object is composed) and that in series the resistance increases as } \\
\text { more elements are added and in parallel the resistance decreases } \\
\text { as more elements are added. }\end{array}$ & $5,14,23$ \\
\hline $\begin{array}{l}\text { (5) Interpret pictures and diagrams of a variety of circuits inclu- } \\
\text { ding series, parallel, and combinations of the two. }\end{array}$ & $4,13,22$ \\
\hline Circuit layout (objectives $1-3,5$ ) & \\
\hline
\end{tabular}




\begin{tabular}{|c|c|}
\hline \multicolumn{2}{|l|}{ Energy objectives $(6-7)$} \\
\hline $\begin{array}{l}\text { (6) Apply the concept of power (work done per unit time) to a } \\
\text { variety of circuits. }\end{array}$ & 2,12 \\
\hline $\begin{array}{l}\text { (7) Apply a conceptual understanding of conservation of energy } \\
\text { including Kirchhoff's loop rule ( } \Sigma \mathrm{V}=0 \text { around a closed loop) and } \\
\text { the battery as a source of energy. }\end{array}$ & 3,21 \\
\hline \multicolumn{2}{|l|}{ Current objectives (8-9) E } \\
\hline $\begin{array}{l}\text { (8) Understand and apply conservation of current (conservation } \\
\text { of charge in the steady state) to a variety of circuits. }\end{array}$ & 8,17 \\
\hline $\begin{array}{l}\text { (9) Explain the microscopic aspects of current flow in a circuit th- } \\
\text { rough the use of electrostatic terms such as electric field, potential } \\
\text { differences, and the interaction of forces on charged particles. }\end{array}$ & $1,11,20$ \\
\hline \multicolumn{2}{|l|}{ Potential difference (voltage) (objectives 10-11) } \\
\hline $\begin{array}{l}\text { (10) Apply the knowledge that the amount of current is influenced } \\
\text { by the potential difference maintained by the battery and resis- } \\
\text { tance in the circuit. }\end{array}$ & $7,16,25$ \\
\hline $\begin{array}{l}\text { (11) Apply the concept of potential difference to a variety of cir- } \\
\text { cuits including the knowledge that the potential difference in a } \\
\text { series circuit sums while in a parallel circuit it remains the same. }\end{array}$ & $6,15,24,28,29$ \\
\hline Current and voltage (objectives 8 and 11 ) & 26 \\
\hline
\end{tabular}

\section{Results}

The results presented in this paper were collected from 2013 to 2017. A total of 494 students from different Engineering modalities were analyzed in our research. To organize the discussion, we divided in two parts: adapted Open Question and DIRECT.

\subsection{Open Question}

In Open Question, students can freely write their answers and reasoning. We considered correct only those who gave the proper explanation to their reasoning. Table 1 shows the average results for these four years.

Table 1 . The percentage average of students who answered correctly the question present in Frame 1 in pre and post-test.

\begin{tabular}{|c|c|c|c|}
\hline Question & Pre(\%) & Post $(\%)$ & $\Delta$ (Post-Pre) $(\%)$ \\
\hline I & 22,8 & 34,2 & 11,4 \\
\hline II & 20,8 & 33,2 & 12,4 \\
\hline III & 40,9 & 46,3 & 5,5 \\
\hline
\end{tabular}

Students had a growth in all three questions. Among major misconceptions, students have about circuits, they reason in ways that differ from scientific reasoning. The "sequential reasoning" results in a "before and after" examination of the circuit. This fact could be observed in the idea that the light bulb closest to the battery consumes current or voltage. We noticed this misconception in the pre-test of several students, as shown below:

(Part I) $A>B$ e $C=D . A>B$ because $A$ uses up the energy that was going to $B$. $C=D$, because both receive the same current (Student 1). 
18 ISSN: 2358-1271. Int. J. of Alive Eng. Educ. (IJAEEdu). (Online). Goiânia, v. 2, n. 5, p. 18-22, July/Dez. 2018.

(Part II) $A=C=D>B . A, C, D$ receives the same amount of current, but $A$ uses up the current (Student 2).

(Part III) $A>C=D$. A uses up part of the current that was going to $C$ and D. Nevertheless, $C$ and $D$ receives the same amount of current (Student 3 ).

(Part III) $A>C=D$. A has more luminosity than $C$ and $D$ (that are the same). That is because $A$ offers more resistance, consuming part of the voltage (Student 4).

Other difficulties that have been frequently verified, refer to the divided current between the light bulbs, as the two statements below show:

(Part I) $A=B ; C=D$. Series: $A$ and $B$ have the same current $A / 2$ since the lamps are identical (Student 5).

$A=B$. The current is divided $A / 2$ equally since the lamps are identical. $C=D$ The current is equal to $A$ in the two lamps (Student 6).

These finds indicate that when asked to reason qualitatively, students tend to approach circuit problems gradually as opposed to considering it as a whole system, not applying a consistent model.

As mentioned previously, in laboratory classes, students realize inquiry activities which students make predictions, observations and comparisons. These activities help students overcome misconceptions about electric circuits. An interesting point that we observed is that students answer the post-test using more conceptual and argumentative justifications than they did in the pre-test, where answers were based on equations. It shows us that students' qualitative argumentation has increased once they built a more complex reasoning. These results are consistent with data observed in others researches ${ }^{1,3,10-13}$. For instance, McDermott and Schaffer $(1992)^{1}$, similarly reported a produced higher achievement post-test scores, more positive student attitudes, and higher levels of student persistence.

\subsection{DIRECT}

We compared correct answers in pre and post-tests of 494 students from different Engineering modalities, as shown in Graphic 1. Student's performance in post-test have improved in almost all questions. Questions which less than 50,0\% of students answered correctly in post-test are indicated by an arrow.

The Graphic 1 has the percentage of students who got right each of the questions, what we call "correct answers", and in the vertical axis and the number of the question is exhibited in the horizontal axis.

To examine the results, we organized students' DIRECT responses according to the 11

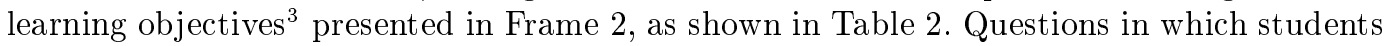
exhibit difficulties (questions which less than 50,0\% of students answered correctly in posttest) are related to objectives 6,9 and 11 .

Objective 6 (Questions 2 and 12) is about power and work, as show in Frame 3. Power is not treated extensively in our laboratory and work is not even mentioned. It shows us that we can map student's difficulties even from lectures about Electricity and Magnetism, once student's study them before the laboratory. The same can be said about objective 9 (Questions 1 and 11) (see Frame 3), which treats about microscopic aspects of electric current, what can explain students decrease in post-test for question 11, once we interpret their answers as guesses. These results provide an indication that research is a good way to improve learning, since we have been mapping students' difficulties for ten years and 
proposing activities to help students overcome them.

Question 21 requires students to analyze a schematic circuit and identify, among four realist representations, which one is similar to the scheme. Student's difficulties at this point can be related to a struggle interpreting a schematic circuit in a life similar representation.

Indeed, the objective 11 has 6 questions related to it. In questions 23 and 27, the results were not satisfactory.

Question 23 asks students to relate the increase in current to the potential difference of the battery. When they don't answer it correctly, it shows that they have difficulties understanding that potential difference generates current, but not the opposite. In question 24 the difference between pre and post-test scores is very similar and most of the students got it right, so we don't focus on them in this work.

In question 27, students can't tell the potential difference between two points in the electric circuit, when there is an open switch. During the laboratory, students make experiments involving measurement of potential difference in many similar circuits that the one used in the question. We could notice that students struggle to get the right measurements, what reinforce the idea that it is a difficult idea to be explored with them. We can notice that their answer in post-test have decreased comparing to pre-test, showing that the activities we proposed to help them only created more confusion and need to be restructured.

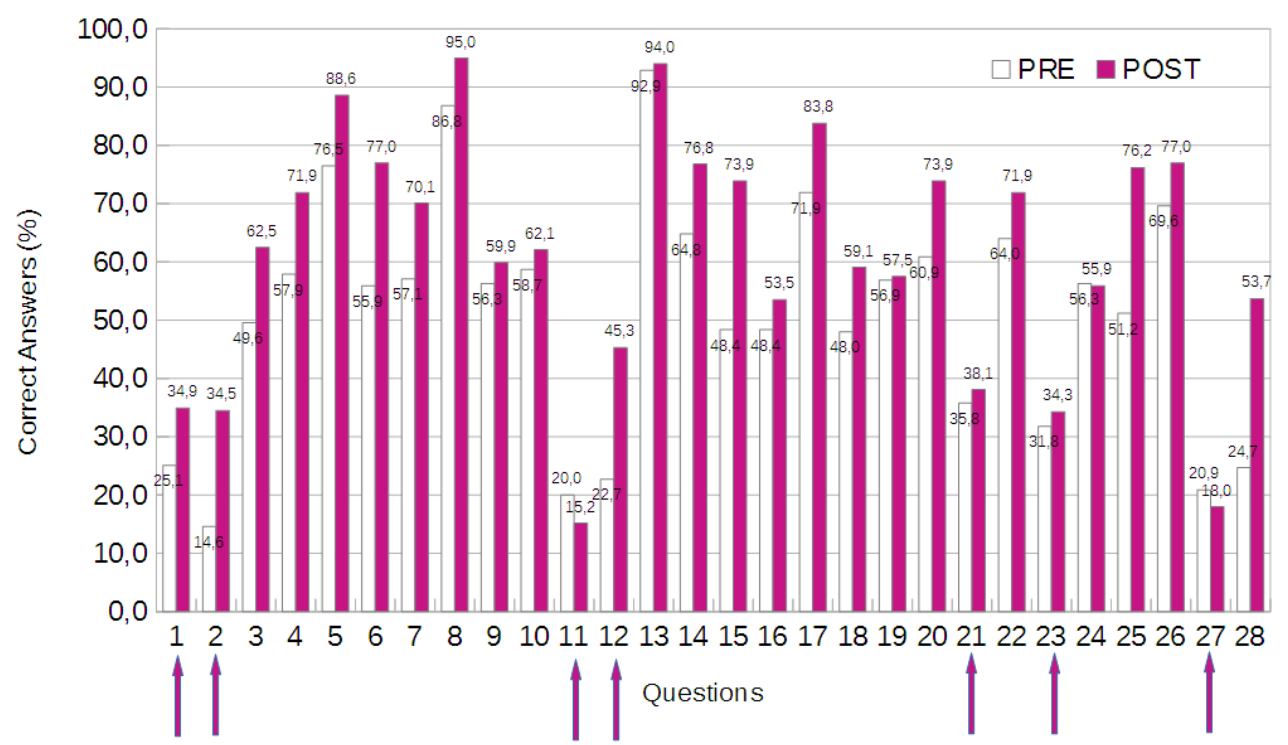

Graphic 1. Generic Graphic of the percentage of students who answered correctly each question.

The arrows indicate questions that less than $50 \%$ of students answered correctly.

Table 2. Represents the percentage of correct answers in pre and in post-tests, according to the objectives.

\begin{tabular}{|c|c|c|c|c|}
\hline Objectives & Questions & Pre(\%) & Post(\%) & $\Delta$ (Post-Pre)(\%) \\
\hline 2 & $9,18,26$ & 58,0 & 65,3 & 7,4 \\
\hline 3 & 26 & 69,6 & 77,0 & 7,3 \\
\hline 4 & $5,14,22$ & 68,4 & 79,1 & 10,7 \\
\hline 5 & $4,13,21$ & 62,2 & 68,0 & 5,8 \\
\hline
\end{tabular}




\begin{tabular}{|c|c|c|c|c|}
\hline 6 & 2,12 & 18,6 & 39,9 & 21,3 \\
\hline 7 & 3,20 & 55,3 & 68,2 & 13,0 \\
\hline 8 & $8,17,25$ & 70,0 & 85,0 & 15,0 \\
\hline 9 & 1,11 & 22,6 & 25,1 & 2,5 \\
\hline 10 & $7,16,24$ & 53,9 & 59,9 & 5,9 \\
\hline 11 & $6,15,23,25,27,28$ & 38,8 & 55,5 & 16,7 \\
\hline
\end{tabular}

Frame 3. Objectives and questions that students exhibit difficulties, even after attending to the laboratory classes.

Objective 6 -Apply the concept of power work done per unit time to a variety of circuits. Questions:

2) How does the power delivered to resistor $A$ change when resistor $\mathrm{B}$ is added as shown in circuits 1 and 2 respectively?

(A) Increases

(B) Decreases

(C) Stays the same

12) Consider the power delivered to each of the resistors shown in the circuits below. Which circuit or circuits have the least power delivered to it?

(A) Circuit 1

(B) Circuit 2

(C) Circuit 3

(D) Circuit $1=$ Circuit 2

(E) Circuit $1=$ Circuit 3

Objective 9 - Explain the microscopic aspects of current-flow in a circuit through the use of electrostatic terms such as electric field, potential differences, and the interaction of forces on charged particles.

Questions:

1) Are charges used up in a light bulb, being converted to light?

(A) Yes, charges moving through the filament produce "friction" which heats up the filament and produces light.

(B) Yes, charges are emitted.

(C) No, charge is conserved. It is simply converted to another form such as heat and light.

(D) No, charge is conserved. Charges moving through the filament produce "friction" which heats up the filament and produces light.

11) Why do the lights in your home come on almost instantaneously?

(A) Charges are already in the wire. When the circuit is completed, there is a rapid rearrangement of surface charges in the circuit.

(B) Charges store energy. When the circuit is completed, the energy is released

(C) Charges in the wire travel very fast.

(D) The circuits in a home are wired in parallel. Thus, a current is already flowing.

\section{Conclusions}

In this work, we analyzed students' answers to pre and post-tests (Open Question and DIRECT) where we could identify common difficulties in Engineering students about DC Electric Circuits. These results show they do not have much practical experience with inner workings of simple circuits.

In the Open Question, results showed an increasing of 18,5\% (part I), 18,5\% (part II), $7,5 \%$ (part III) in the percentage average of students, between 2013 and 2017. It also 
exhibited difficulties cited in literature, as current being consumed and confusion between current, resistance and voltage. Although these results may reflect multiple factors affecting learning in student laboratory, they show that students do not have experience in qualitative reasoning. Typically, in traditional lectures, students are asked to solve many homework exercises or examinations involving numerical calculations. Thus, when confronted with a qualitative question, they begin by writing down equations and trying to calculate. Using inquiry activities, we noted that student's answers in post-test are more structured in logic reasoning and less in formulas, comparing to pre-test.

Through DIRECT, we observed that some difficulties persist, like microscopic aspects of electric current and about the concept of power. These subjects are not deeply treated in our laboratory, but they are in the lecture's classes. Thus, we could identify conceptual difficulties from other classes. In previous studies, we also have noticed similar difficulties in students of from other courses, using DIRECT and the open question ${ }^{10-13}$. Also, between 2013 and 2017, the average percentage of students who score more than half of the test increased in $10,2 \%$.

Students show significant and positive effects during a guided-inquiry laboratory course, once they structure their answers based on concepts. We also identified a variation in aspects of student attitudes like: interest, understanding and acceptance. Our experience has shown that research for improving practice is fundamental to overcome persisting difficulties and is a long-term action. Also, the use of different resources such as homework activities on the internet, videos and computer simulations proved to be useful as supplement materials. We believe that the improvements and students' difficulties pointed in this work could serve as impulse to the proposal of new activities and inquiry teaching strategies, seeking a wide student's formation.

\section{Acknowledgment}

We would like to thank the Instituto de Física de São Carlos (IFSC) and the Universidade de São Paulo(USP) for offering the required structure for us to build a consistent laboratory course and Coordination for the Improvement of Higher Education Personnel (CAPES) for the financial support. We are also grateful to all the professors and students who have contributed directly or indirectly to the development of the Laboratory Guide.

\section{References}

1. MCDERMOTT, L.C.; SHAFFER, P.S. Research as a guide to curriculum development: an example from introductory electricity. Part I: investigation of student understanding. American Journal of Physics, 60(11), 994-1003, 1992.

2. DUIT, R., \& VON RHÖNECK, C. Learning and understanding key concepts of electricity. Connecting Research In Physics Education with Teacher Education, 1-6, 1997.

3. ENGELHARDT, P.V.,BEICHNER, R.J. Students' understanding of direct current resistive electrical circuits, American Journal of Physics, 72(1), 98-115. 2004.

4. BRADLEY J. D. (2001). UNESCO/IUPAC-CTC Global Program in Microchemistry, Pure and Applied Chemistry, 73,1215-1219, 2007.

5. PLANINIC, M. Assessment of difficulties of some conceptual areas from electricity and magnetism using the Conceptual Survey of Electricity and Magnetism. American Journal of Physics, 74(12), 1143-1148. 2006.

6. BLANTON, P. Developing an inquiry lesson, Physics Teacher, 45(1), 56-57. 2007. 
7. MARUŠIĆ, M.; SLIŠKO, J. Influence of Three Different Methods of Teaching Physics on the Gain in Students' Development of Reasoning. International Journal of Science Education. 34(2), 301-326. 2012.

8. BRASIL, CNE/CES 11, de 11 de março de 2002, que institui as Diretrizes Curriculares Nacionais do Curso de Graduação em Engenharia, (Ministério da Educação, Brasília, 2002). Disponível em: $<$ http://portal.mec.gov.br/cne/arquivos/pdf/CES112002.pdf > . Acessed on 04 may. 2018.

9. MCDERMOTT, L.C.; SHAFFER, P.S.Tutorials in Introductory Physics. New Jersey: PrenticeHall. 2002.

10. SANCHES, V.T.; SANTOS, J.F.M.; COSTA, G.G.G.; CATUNDA, T.. Analysis of an Inquirybased laboratory for undergraduate students. 2ND WORLD CONFERENCE ON PHYSICS EDUCATION (WCPE) 2016. Procedings... São Paulo (Brasil) - 2016.

11. SANCHES, V.T.; COSTA, G.G.G.; SANTOS, J.F.M.,CATUNDA, T.. Estudo das principais dificuldades dos alunos em um laboratório investigativo de eletricidade. In: Simpósio Nacional de Ensino de Física, 22, 2017, São Carlos - Brasil. Trabalhos... São Carlos - Brasil, 2017. Available in <http://www1.sbfisica.org.br/eventos/snef/xxii/sys/resumos/T0444-1.pdf $>$. Accessed on: 10 nov 2018

12. SANTOS, J.F.M.; COSTA, G.G.G.; CATUNDA, T.. Análise da inserção de atividades investigativas nas aulas experimentais em um curso de eletricidade e magnetismo no ensino superior. In: Simpósio Nacional de Ensino de Física, 20, 2013, São Paulo. Trabalhos... São Paulo - Brasil, 2013. Available in <http://www.sbf1.sbfisica.org.br/eventos/snef/xx/sys/resumos/T0277-2.pdf $>$. Accessed on: 10 nov 2018

13. SANCHES, V.T.; COSTA, G.G.G.; SANTOS, J.F.M.,CATUNDA, T.. Common Engineering Students Dificulties with DC Electric Circuits in An Inquiry-based Laboratory. In: INTERNATIONAL CONFERENCE ON ALIVE ENGINEERING EDUCATION (ICAEEdu) 2018 Proceedings... Puerto Iguazú (Argentina) - 2018. Available in: <https://icaeedu.emc.ufg.br/up/920/o/ICAEEdu-2018-Proceedings-Online-Resourceversion-3.0.pdf $>$. Accessed on: 10 nov 2018 